\title{
Masas de flanco del recién nacido
}

\author{
DRES. CESAR IzZo S. *, ALFREDO DEL RIO M. * y JUAN J. LATORRE *
}

En el presente trabajo hemos reunido aquellos recién nacidos enviados al Servicio de Cirugía de nuestro Hospital por presentar una masa de flanco durante un examen pediátrico de rutina. No hemos incluido aquellos casos en que el diagnóstico se ha hecho en Anatomía Patológica porque pretendemos hacer un enfoque clínico sobre las posibilidades diagnósticas que se plantean ante el hallazgo de un tumor de uno o ambos flancos.

Hemos reunido 50 recién nacidos en los últimos 10 años y todos ellos han sido estudiados clínicamente, mediante pielografía y además mediante intervención quirúrgica y biopsia.

Material. De los 50 casos estudiados 40 eran unilaterales y sólo 10 bilaterales, comprobándose los siguientes diagnósticos:

\section{Masa unilateral.}

Riñón multicístico unilateral

29 casos

Hidronefrosis

Poliquístico unilateral

Hemorragia suprarrenal

Neuroblastoma

Fibroma hepático

Riñón doble

3 casos

2 casos

2 casos

1 caso

1 caso

2 casos

\section{Masas bilaterales.}

Riñón poliquístico bilateral

Riñón aumentado palpable

Hidronefrosis

Riñón multicístico bilateral

Es indudable que el mérito diagnóstico corresponde al clínico que practica el examen y palpa la masa y es muy importante consignar la uni o bilateralidad de la masa porque el diagnóstico es

\footnotetext{
"Hospital de Niffos "Luis Calvo Mackenna". Santlago, Chile.
}

completamente diferente como también el enfoque terapéutico posterior. Debido a la diversidad de los diagnósticos hemos creído conveniente analizar cada grupo separadamente.

\section{MASAS DE FLANCO UNILATERALES}

\section{Riñón multicístico:}

Es el grupo más importante de la serie y constituye la primera causa de masa de flanco unilateral en el recién nacido. En nuestros 29 casos se presentó como una masa indolora y lobulada y de consistencia quística que ocupaba todo el flanco y a veces gran parte del hemiabdomen respectivo. La pielografía mostró invariablemente una exclusión del lado afectado y con altas dosis de contraste pudo observarse en algunas ocasiones la opacificación de las paredes de los quistes. En todos se practicó la extirpación de la masa quística hallándose un uréter atrésico o ausente que sólo en un caso fue quístico en su parte proximal.

Los pacientes fueron seguidos entre 2 a 13 años con evolución satisfactoria en la mayoría. Fallecieron 4: 1 prematuro de 1.600 grs., 2 niños con malformaciones múltiples con hidronefrosis del riñón opuesto y 1 niño por sepsis a estafilococo después de una infección severa de la herida operatoria.

Puede decirse que todo recién nacido con una masa de flanco unilateral y exclusión pielografica es un riñón multicístico hasta que no se demuestre lo contrario.

\section{Hidronefrosis:}

Sólo pesquisamos 3 casos de hidronefrosis mediante la palpación de la masa blanda y redondeada que en la pielografía mostró una di- 
latación pielocaliciaria importante. El problema diagnóstico se suscitó en un caso en que la pielografía mostró exclusión. Intervenido con el diagnóstico de riñón multicístico se halló un riñón de parades muy delgadas y con daño irreversible que determinó una Nefrectomía.

\section{Riñón poliquístico unilateral:}

En este grupo reunimos 2 casos en que el riñón tenía una imagen pielográfica granulosa en un caso y de aspecto bastante normal en otro pero a la exploración quirúrgica se observó lesiones quísticas de la superficie y aspecto tumoral blanquecino. La biopsia mostró microsquistes y no ha sido posible determinar la función real ya que el lado opuesto era normal.

\section{Hemorragia suprarrenal:}

La corteza fetal de la suprarrenal sufre una involución por citolisis en los primeros días de vida determinando microhemorragias frecuentes $(45 \%)$. Si le hemorragia es patológica forma un hematoma palpable externamente como una masa de flanco. Los casos bilaterales son generalmente diagnosticados en la autopsia.

De 9 casos descritos en nuestro Servicio sólo hemos podido comprobar 2 de ellos mediante pielografía y lumbotomía. Nuestra cautela diagnóstica se ha derivado de 3 casos en que la evolución posterior demostró pielografías normales; 2 casos que resultaron ser duplicaciones renales y un caso de neuroblastoma que se analizará a continuación.

Creemos que esto se deriva de la dificultad en interpretar la imagen pielográfica con impresión del polo superior y las calcificaciones lineares del hematoma.

\section{Tumores:}

Hay sólo dos casos de tumores en la serie:

Un caso de tumor maligno que se presentó como una masa de flanco derecho en que la pielografía mostró un rechazo hacia abajo del riñón respectivo con una calcificación dudosa. Con el diagnóstico de hemorragia suprarrenal se dejó en observación. La persistencia de la masa a los 3 meses determinó una laparatomía exploradora que reveló un tumor suprarrenal redondeado y un hígado moteado. La masa extirpada resultó ser un neuroblastoma y la biopsia hepática mostró matástasis.

Después de recibir radioterapia hepática y quimoterapia, la niña se halla bien 4 años después de la intervención.

Otro recién nacido con una masa derecha y rechazo de los cálices superiores tenía un fibro- ma del borde posterior del hígado que fue extirpado con éxito.

Riñón doble: 2 casos fueron diagnosticados equivocadamente como hemorragia suprarrenal con pielografías de difícil interpretación. Controlados años después se evidenció una duplicación unilateral del lado aumentado, a pesar de que con la evolución la masa se hizo dudosa y discutible.

\section{MASAS DE FLANCO BILATERALES}

\section{Riñón poliquístico bilateral:}

6 casos de niños de aspecto normal que presentaban tumores bilaterales de gran tamaño y sólidos. La pielografía mostró débil contraste del riñón con imágenes arborescentes y ausencia de pelvis renal y uréter. En un caso hubo exclusión renal bilateral debido a uremia precoz y el diagnóstico se hizo mediante biopsia abierta.

5 niños han fallecido y uno sobrevive con severa insuficiencia renal a los pocos meses de edad.

Las autopsias mostraron microquistes en ambos riñones y fibrosis hepática que agravó el pronóstico. No hemos tenido ocasión de observar la enfermedad poliquística familiar con quistes en otros parénquimas como el páncreas, pulmón, etc.

El pronóstico es pésimo en la forma de recién nacido debido al escaso parénquima funcionante que no permite una adecuada función renal.

\section{Riñones palpables:}

Hemos tenido prematuros a niños de término en que la pared abdominal poco musculada, la posición baja del riñón, el gran tamaño de las suprarrenales y otras circunstancias que favorecen y facilitan la palpación, han hecho que pensemos en la existencia de un tumor renal bilateral. Mencionamos 2 casos en que tuvimos que llegar a la pielografía para constatar la normalidad de ellos.

En otras ocasiones la clara lobulación del riñón del recién nacido simula una lesión quística.

\section{Hidronefrosis :}

Sólo en una ocasión se halló una masa bilateral blanda que resultó ser una hidronefrosis bilateral. Es posible que haya casos que pasan inaduertidos porque las masas son de difícil palpación si no existe una tensión aumentada dentro del riñón.

\section{Riñón multicístico bilateral:}

Esta rara situación apareció en un recién nacido en que se palpaba una masa izquierda pero 
que mostró una exclusión pielográfica bilateral. La exploración quirúrgica demostró un riñón multicístico izquierdo casi unido a un riñón derecho también quístico pero de tamaño pequeño. El niño fall-ció a los pocos días en anuria.

Comentario. Para el diagnóstico de una masa de flanco es muy importante considerar la uni o bilateralidad de la masa: Si la masa es unilateral y de consistencia quística se pensará en un riñón multicístico y si por cl contrario la masa es sólida y bilateral sugiere un riñón poliquístico.

No podrá avanzarse más sin recurrir a la pielografía intravenosa que a pesar de la dificultad técnica propia de esta edad, permite casi invariablemente hacer un diagnóstico correcto.

Fuera de los casos confirmados de riñón poliquístico será obligatorio hacer una exploración quirúrgica que verifique el diagnóstico.

La exploración quirúrgica no deberá emprenderse con precipitación sin contar con una pielografía o sin que el riñón esté en buenas condiciones ginerales o peso razonable ya que es poco probable que se trate de una masa maligna (un caso de 50). Esto es especialmente valedero en los casos de riñón multicístico en que puede arriesgarse la vida del paciente en una intervención que no tiene ninguna premura (prematuro de 1.600 grs. fallecido por infección post operatoria).

Todas las masas bilaterales fueron de origen renal y de las unilaterales sólo 4 fueron extrarenales (una hepática y 3 suprarrenales).

En general se prefirió el uso de laparatomía exploradora y sólo se usó lumbotomía en aquellos casos de hidronefrosis o en riñones multicísticos de diagnóstico preciso.

No hemos comprobado ningún caso de Tumor de Wilms del recién nacido a pesar de haberse planteado la sospecha clínica en más de una oportunidad.

\section{SUMMARY}

A review of 50 newborns presenting a mass in the flank is presented.

The nature of this mass is only possible by means of a Intravenous pyelogram and ultimately on the basis of a surgical exploration.

When the mass is unilateral and cystic the more likely cause is a Muticistic kidney. The absence of contrast in the I.V.P. almost confirms the proposed diagnosis.

The hard bilateral masses 'ead us to the diagnosis of Policystic kidneys.

49 of 50 cases resulted into beningn tumours.

The only malignancy of the serie corresponds to a Neuroblastoma explored with the diagnosis of adrenal hemorrhage succesesfuly treated with surgery and radiotherapy.

\section{REFERENCIAS}

Longino, L.A. Abdominal masses in the newborn infant. Pediatrics: 1958, 21: 596.

Izzo, C. Riñón multicístico del recién nacido. Arch. Soc. Ciruj. Chile 1966, 18, 410.

Wedge, J. Abdominal masses in the newborn: 63 cases. J. of Urology 1971, 106: 770. 